\title{
Investigating Indian Retail Investor Behavior through the Lens of Prospect Theory
}

\author{
Aseem Singru ${ }^{1}$ and Zoey Chopra* \\ ${ }^{1}$ Inventure Academy, Banglore, India \\ \#Advisor
}

\section{ABSTRACT}

The paper explores how prospect theory of loss aversion (Kahneman \& Tversky 1979) can help explain retail investor behavior in India with respect to small-cap and mid-cap stocks during periods of crisis which may influence emotional sentiments as well as stock markets. Two distinctly separate periods were analyzed and compared: the Great Recession (2008-09) and the COVID-19 global pandemic (2020-21). A combination of qualitative and quantitative methods was used - a literature review of past studies, detailed interviews with experts, and cross-correlation analysis sentiment and market indices. Statistical correlation analysis of investor sentiment was done versus stock market index movement during the two time periods. Results indicate that positive sentiment and negative sentiment have immediateterm positive and negative relationship respectively with investor behavior, and how loss aversion was stronger during 2008 than 2020. Study also identifies differences in reference points between the two periods, which is consistent with prospect theory in terms of the role of reference point in determining degree of loss-aversion. Expert interviews identified multiple factors such as prior experience with market losses, governmental actions, younger demographics, easier market participation due to technology in 2020 caused the reference point to be different from 2008. Further research needed to understand why the sentiments have an immediate effect on investor behaviors but not in future periods. In contrast, movements in stock markets were seen to have both immediate and future period relationships with sentiment, which suggest some role of herding which needs to be further investigated in future studies.

\section{Introduction}

The Covid-19 pandemic has been an extraordinary period in global economic history and also been a period of emotional turmoil and volatility in India. For stock market investors, the last period which had repercussions in India with similar global impact was the 2008 Great Recession. Looked at from the lens of prospect theory of loss-aversion, this paper studies how Indian retail investing behavior for small and mid-cap stocks during the 2020-21 COVID-19 pandemic compares to that of the 2008-09 Great Recession. Current literature in behavioral finance focuses on the two financial downturns in India in isolation with little comparative study. With a focus on the role of loss aversion in small and mid-cap stock markets, this paper explores how attitudes towards risky assets might differ between financial crises driven by different events: the failure of financial institutions in 2008-09 and the COVID-19 pandemic in 202021. Insights from this study can improve our knowledge of how a more conducive environment for investing can be created in any crisis.

SARS-Cov-2 virus originated from the Wuhan province in China starting in November 2019 and rapidly spread globally, with the WHO (World Health Organization) declaring a global pandemic on March 11, 2020 (WHO Director-General Remarks 2020). The pandemic has resulted in significant negative impacts on economies across the world as months-long quarantines and national lockdowns were enforced by governments. In the Indian context, strict nation-wide lockdowns started on March 242020 and continued till early May, 2020 (Wikipedia 2021). The initial phase of the lockdown from March to May 2020 put restrictions on people from stepping out of their homes. Public 
transport and shops other than essential supplies were closed. Except for very few essential sectors, factories were also closed. Places of work and study such as offices and schools were closed and switched to remote/online working. The economy has been slowly reopened since May 2020. These preventive measures caused the Indian stock market to experience severe downturns across all sectors in the initial months due to uncertainty.

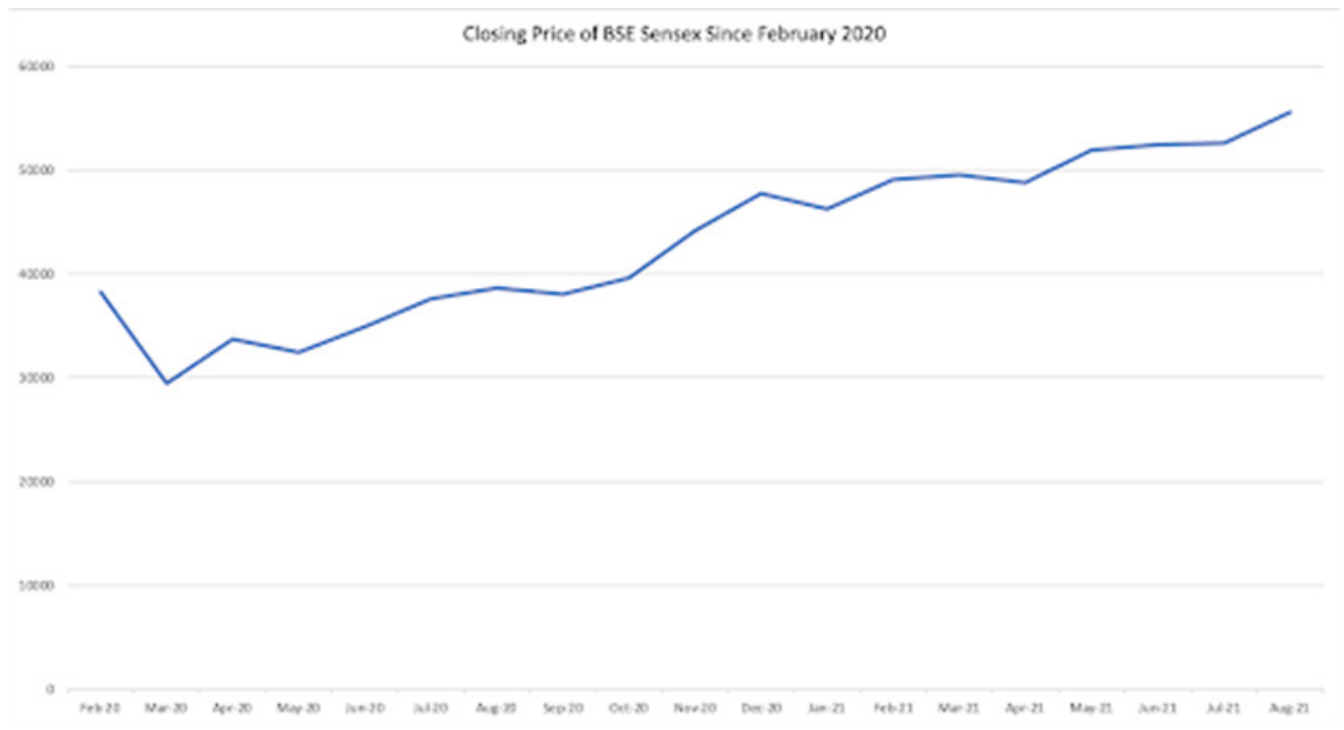

Figure 1: BSE Sensex movement from Feb 2020-Aug 2021

BSE Sensex (stock market index of 30 well-established and financially stable companies listed on the Bombay Stock Exchange), the primary index of Indian stock market (Figure 1), which was at historic highs in mid-Jan 2020 (41,953 on Jan 14 2020), fell to a point 40\% lower $(25,981)$ by Mar 23 2020, right before the national lockdown started. This was followed by volatility beginning in late March 2020 till early June 2020 (period of strict national lockdown), followed by a relatively steady increase since then to exceed the pre-pandemic high mark by end of the year 2020 as the government started rolling out various stimuli and the economy started to re-open.

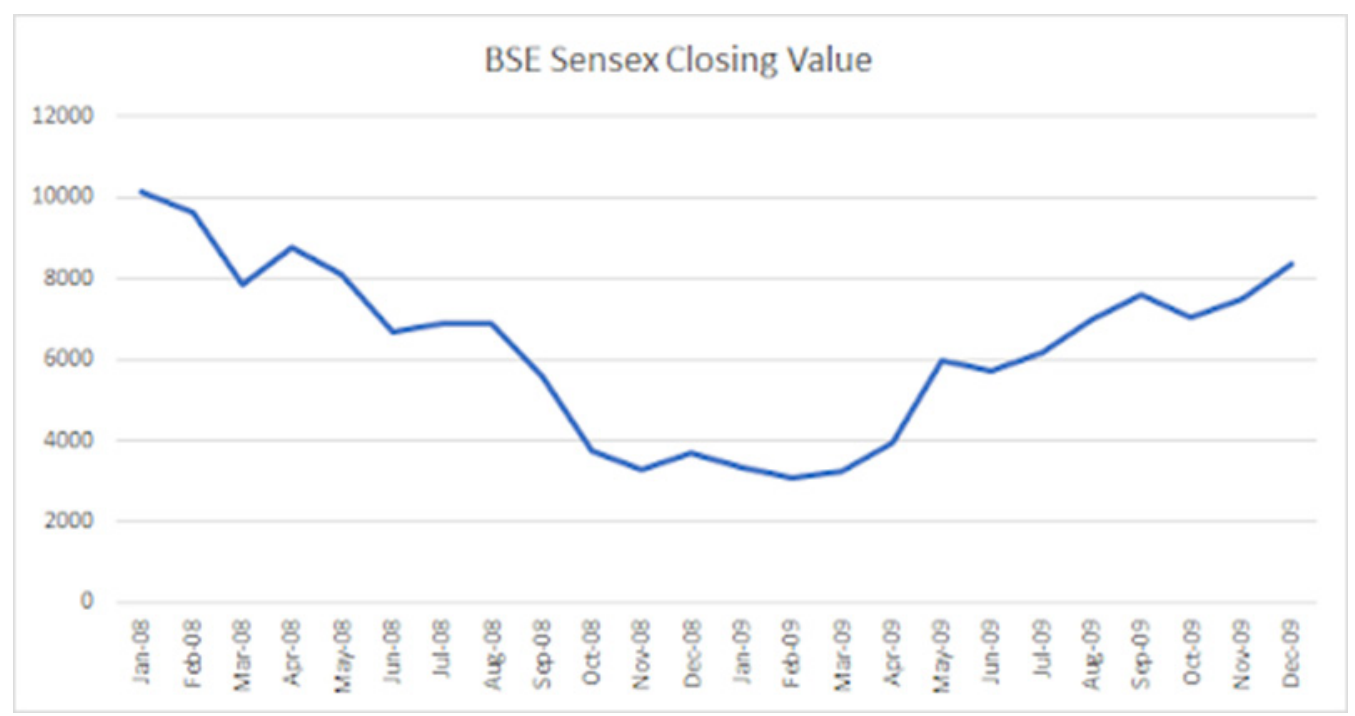

Figure 2: BSE Sensex movement from Jan 2008-Dec 2009 
In comparison, the situation was different in the 2008-2009 Great Recession. That financial crisis emerged from the United States' subprime mortgage driven liquidity crisis. The lack of liquidity in global banking system engulfed the world, leading to adverse impacts on economic growth and employment and leaving stock markets in ruins (Verick and Islam, 2010). The Indian stock market, which was on a bull-run prior to this crisis, was significantly affected (Figure 2). The BSE Sensex experienced a 13,000 point fall over 10 months in 2008 (Economic Times, 2020), which is an estimated $61.9 \%$ fall in value of the index. Full recovery to pre-recession growth was not achieved until September of 2010 (Groww.com, 2021).

While the Great Recession and Covid-19 Pandemic were two very different event with vastly different origins, comparing them can contribute valuable knowledge to existing literature: (1) both crises are global in nature; (2) both created fear and uncertainty among retail and institutional investors, (3) the markets show a different type of recovery in the two periods, and The differences in investor behavior in the two periods can help improve our knowledge of how prospect theory and loss aversion work in different circumstances.

A combination of qualitative and quantitative methods was used to conduct the research. First, a literature review of investor behavior in the Indian stock market during the two crises was carried out. Secondly, detailed interviews with several financial industry experts to understand their perspective on retail investor behavior during the two periods were conducted, followed by qualitative analysis. According to the experts, prior experience with market losses, governmental actions, greater maturity, younger demographics, greater usage of search engines like Google, and availability of free-trade platforms were also related to less loss aversion among Indian retail investors in the 2020-21 pandemic compared to the 2008-09 crisis.

This qualitative analysis supplemented quantitative analysis. Statistical correlations of investor sentiment (hope and fear) versus stock market movements during the two periods were explored. As part of the study, it was evaluated if investor sentiments have both immediate and delayed impact on stock market price (index), as well as vice versa, because that can help explain how loss-aversion works in such situations. Results indicate that positive sentiment and negative sentiment have immediate-term positive and negative relationship respectively with investor behavior, and this relationship was noticeably stronger during the 2008 recession compared to the pandemic. This relationship between sentiments in current periods does not influence future stock movements to a significant extent. However, stock market movement in the current period (i.e. investor behavior) shows a longer term (lagged) relationship with sentiments in future periods, with this observation being stronger in 2008 than 2020.

This paper concludes that factors such as greater government intervention, younger demographics among investors, and greater internet usage were correlated with the lower levels of loss aversion among Indian investors in 2020-21 compared to 2008-09. Second, the results show how governments and financial firms can provide policy and trading platform assistance to create a more conducive environment for investors to trade in risky financial assets, and to reduce likelihood of loss-aversion bias. Effectively, the factors that were correlated with lower loss aversion in 2020-21 should be points of focus for the Indian government and financial sector to focus on to improve market participation in risky investments. Finally, the longer-term influence of stock market performance on sentiments suggest that herding bias may also place a role in investor behavior, particularly in the 2008 crisis.

\section{Literature Review}

"Rational economic behavior" describes when individuals make decisions that provide them with the optimal level of utility, or satisfaction (Hall, Investopedia 2019). The Efficient Market Hypothesis presents the idea that the market is efficient in that stock prices reflect all available information (Konstantinidis et al., 2012). However, an alternate approach to study economic behavior states that individuals may behave irrationally and with incomplete information, and optimal utility from the perspective of rational individuals is not achieved. The study of this irrational behavior in financial markets is classified as behavioral finance. 
Behavioral finance emerged as an area of academic study to understand heuristics and cognitive biases that might guide individuals' actions and reactions in financial investment contexts. The field broadly derives real-world implications from applications of prospect theory. While expected utility theory attempts to approximate the utility (or satisfaction) that is gained from any given action using expected value calculations, prospect theory (Kahneman and Tversky, 1979) outlines an alternative model.

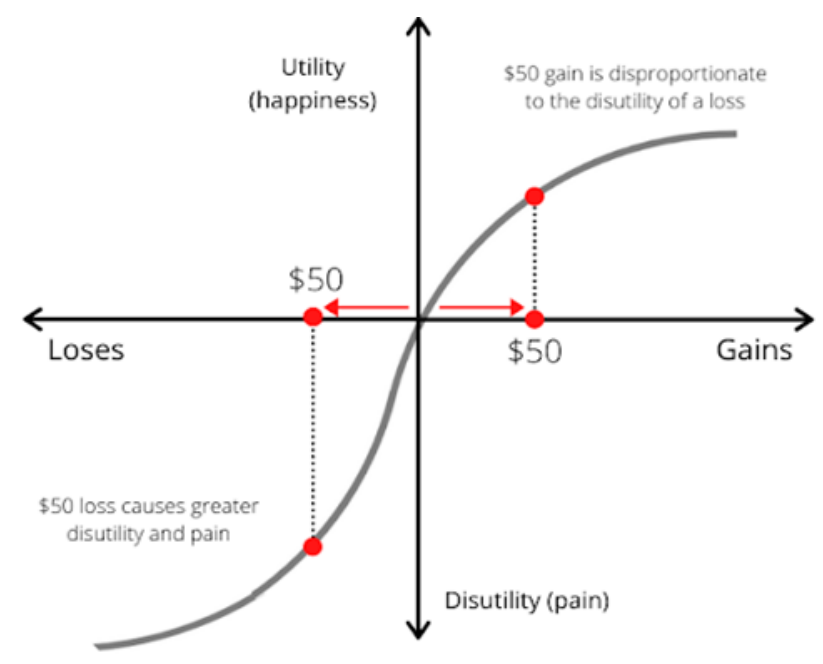

Figure 3: Hypothetical Value function (Source: BoyceWire)

The value function described in Figure 3 (emotional utility magnitude versus gain//loss amount) asserts that individuals experience losses more perceptibly than gains even if losses and gains are equal in monetary terms. As a result, prospect theory expects individuals to exhibit loss aversion. The negative emotional impact of losses of a certain amount (e.g. 50 dollars) is greater than the positive impact of a gain of the same amount. The position of this reference point (or context) is dynamic, thus causing the weighting of gains and losses to change. For example, before winning the 50 dollars, if the individual had experienced a gain of 500 dollars, the emotion is different than if they had experienced a gain of 10 dollars.

The overweighting of probabilities causes individuals to become risk-averse when they are in the positive domain of the value function and risk-seeking when in the negative domain. Kahneman and Tversky carried out experiments to identify how individuals view monetarily equivalent outcomes when framed differently (i.e. in different contexts), concluding that on average individuals preferred events with more certainty.

Given that both 2008 and 2020 were significantly different time periods in India with different macro-economic contexts prior to the crisis events, the reference points for investors behavior were different. Also, both crises created situations where there was fear of losses among investors. In 2008 investors had experienced significant gains in months prior to the crisis, while in 2020 they had more experience with losses and relatively flat markets in previous months. By studying two different reference points and the reaction to the fear of losses therein, the study seeks to determine whether investor behavior (in terms of loss aversion and application of prospect theory) was similar or different and the potential reasons for it.

\section{Behavioral Attributes of Indian Investors}

Attempting to determine the attributes of Indian investors on average will help us determine whether the investor behaviors exhibited in 2008-2009 and 2020-2021 were anomalous or consistent with less unusual times and whether certain heuristics, namely loss aversion, were amplified. Chandra and Kumar (2012) found the presence of behavioral biases including anchoring, availability bias, representativeness bias, overconfidence, and regret aversion in Indian 
investor behavior. A similar study by Dutta et al. (2020) found that six prominent behaviors among Indian individual investors include regret, panic, cognitive dissonance, herding, anchoring, and heuristics in this order. These behaviors have been defined in the appendix questionnaire and also analyzed in the qualitative results section.

Other literature suggests more specific behavior under specific conditions. Mushinada (2020) finds that Indian investors display overconfidence bias as a result of over-reliance on private information, causing unrestrained volatility. Subsequently, when they experience losses, it causes a shift to underconfidence.

\section{Herding Behavior}

Herding behavior occurs when individuals follow the decisions and actions of others and groups under the assumption that others have done their research and are making informed decisions. Dhall and Singh (2020) presented that Indian investors demonstrated herding behavior for the automobile, IT and pharmaceutical industries under bull market conditions for the 2020 pandemic, while bear market conditions display herding behavior in the media and entertainment industries. Comparably, Poshakwale and Mandal (2014) argue that herding behavior is more defined for bull market conditions, as concluded by their examinations of the Indian stock markets during the 1997 to 2012 period. Bhaduri and Mahapatra (2013) affirmed that there is evidence of herding behavior in Indian stock markets, with a particularly strong presence during the 2008 crash compared to more normal periods.

In comparison, the 2020-2021 pandemic's financial crisis occurred under special circumstances not seen in the past. The crisis did not evolve from the structural issues of the finance sector unlike the 2008-2009 crisis, but rather, from a public health pandemic. Evidence from other countries suggests that the pandemic period demonstrated less loss-aversion and increased stock activity in other markets unlike the 2008 crisis where investors exited the markets. Ortmann et al. (2020) find that Chinese students in Wuhan during the outbreak of COVID-19 had significantly lower general desire for risk. Moreover, individuals with greater exposure to the pandemic had less inclination for risk and held pessimistic views on the economy. Trading intensity rose by $13.9 \%$ when COVID-19 cases doubled, with investors opening greater stock and index positions, but did not shift to safe havens or high risk assets. In the United States economy, Vasileiou (2020) presents evidence that during the COVID-19 pandemic individuals in the US economy overweighted the recent information of stimulus packages boosting the economy which has a positive effect on investor behavior, and underweighted the persistent health risks from the Covid pandemic. Hirovenen (2021) found that confirmation, herding and representativeness bias are the most influential biases during the pandemic.

As the review of the prior studies indicates above, both 2008 and 2020 were situations in which markets crashed over short durations, and investors faced fear and uncertainty due to economic (e.g. job losses) worries or health concerns. Since prospect theory (loss aversion theory) is related to putting higher weight on potential losses rather than potential gains, and the role of reference point or context in determining those weights, the comparison of the two periods helps improve understanding of how the theory works in these circumstances.

To capture the nature of investor bias, sentiments can be measured in a few different ways. Sentiment indices are traditionally based on surveys of investors to gauge investor sentiments at a current period of time and can be helpful in determining how and which initial sentiments may be a cause or result of irrational investor behavior. Vasileiou (2020) states that fear is a better indicator than economic variables in predicting investor behavior, and Google searches can help incorporate the behavioral influence on financial models. Lim and Stridsberg (2015) find that Google-based sentiment indices are an accurate reflection of retail investor sentiments, as such investors are much more likely to use search engines rather than specialized industry tools for stock information. Additionally, OliveiraBrochado (2019) validates in Portugal that Google search-based sentiment measures can be used to represent investor beliefs and are correlated with stock market performance.

\section{Methods}

\section{Qualitative Analysis}


Due to limited literature concerning behavioral economic trends of Indian retail investors in both the 2008-09 period and 2020-21 period, structured in-depth interviews were carried out with financial industry professionals to gain improved understanding of the behavior of Indian retail investors in both crises. In addition, the responses from interviewees provided qualitative data that provided greater context to the sentiment-based indices created and will allow us to elicit conclusions about loss aversion in investors during 2008-09 compared to 2020-21.

Interviewees were chosen based on (1) amount of experience working in the financial sector; (2) ease of access for the author; and (3) availability for interviews. A total of six interviews were carried out after contacting seven individuals; each interview lasted from 45 minutes to 60 minutes. The profiles of the respondents and the structured questionnaire created for the interviews are listed in the Appendix.

\section{Correlation Analysis using Google Trends \& Stock Index}

As per Securities \& Exchange Board of India (SEBI) classification, stocks fall in three categories in the Indian stock market - Small-cap (market cap < INR 50 Billion), Mid-cap (market cap INR 50-200 Billion) and Large-cap (market cap > INR 200 Billion). Small and Mid cap stocks are traditionally riskier and more volatile than Large-cap stocks and hence provide an opportunity to research behavior of Indian investors under more challenging conditions such as the 2008 or 2020 crises. The indices used to represent stock market behavior are the BSE Smallcap, BSE Midcap, Nifty Smallcap 100 and Nifty Midcap 100. These indices were chosen because they provide industry benchmarks used by the professional investor community and effectively represent the small-caps and mid-caps stocks. The indices include firms that make up a representative sample of the total publicly tradable small-cap and mid-cap company universe in India across the two major stock exchanges (example: BSE Small-cap Index has 894 companies and BSE Mid-cap Index has 106 companies), 2) They all had data available ranging from before 2008 up until 2021 which helped maintain consistency in the number of firms' data being considered during both financial crises and simplified the process of comparison (Note: the exact list of firms in these indices may have changed between the two time periods under study; however the indices ensure that the lists remain representative of the market/sector at that point of time).

Sentiment indices were used in the analysis as a measure of the investor mindset and underlying loss-aversion bias. Sentiments around "fear" were used as a measure of "fear of loss" (which increases loss aversion). Sentiments around "hope" were used as a measure of "hope of gain" or "reduced fear of loss". Google search keywords used for creating the sentiment-indices were chosen when interviewees, in the interviews carried out, were asked "List 2-4 words that you believe indicate fear and hope during 2008-09, and 2-4 words that indicate fear and hope during the 2020-21 Pandemic" (Appendix, Questionnaire, Question 6). For example, "Recession" is a word that may suggest fear, while "Growth" may suggest hope. These words were not synonyms of fear and hope but words that were associated with these emotions at the time of use in 2008-2009 compared to 2020-2021. The limitations of these words is that they are described by the interviewees (industry experts) as indicative of what retail investors used as signs of optimism or pessimism, which may be subjective.

Google Trends data provides the popularity of a word at a specific given point of time and has daily data. This can indicate the sentiments of individuals at that moment as opposed to potentially outdated data (OliveiraBrochado, 2019). In addition, Google Trends can be an effective indicator of retail investors' sentiments as retail investors traditionally rely on search engines to inform themselves about stock market information due to lack of access to formal financial advising (Lim \& Stridsberg, 2015). The tool is easy to access and free to use. The data can be exported for research purposes and is available at a global scale. As Google Search is the most used search engine in India, it can represent a good percentage of all people with free access to the Internet. At the same time, there are some limitations of Google Trends that need to be noted - the tool only gives relative numbers and not absolute numbers (look at the y-axis in Figure 4 below). Some subjects of research might not have internet access. Lastly, the context of the search is not clear as we do not have details on the person. In balance, it is the best among options available for our purpose. 


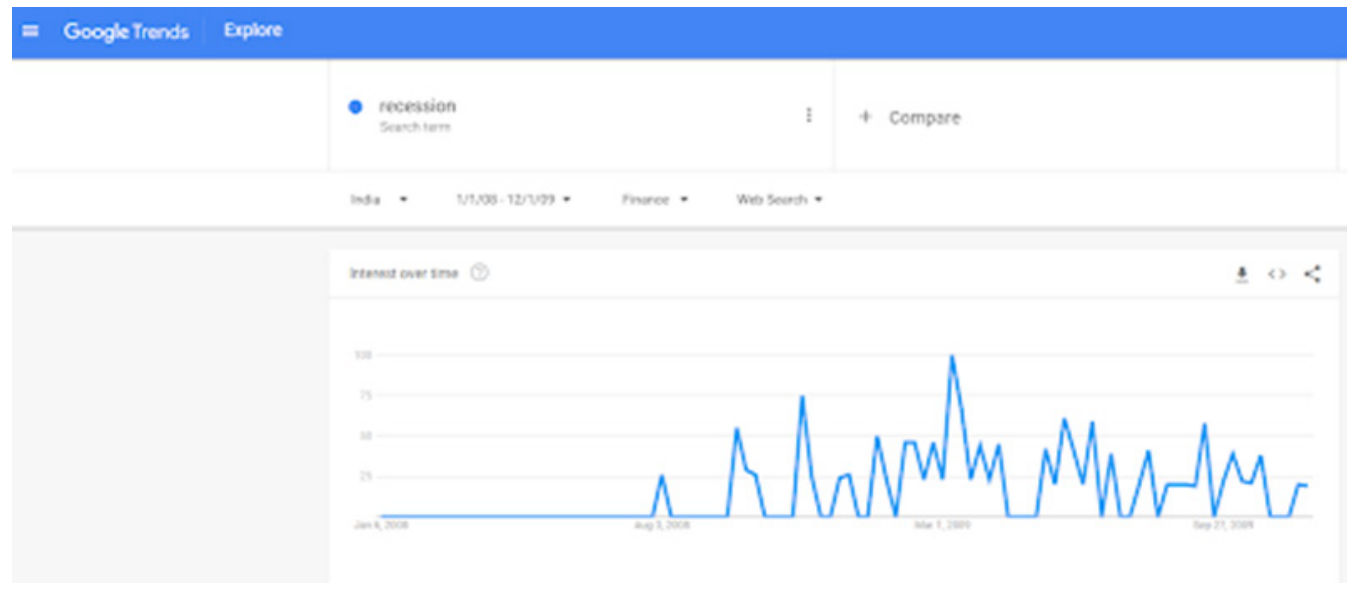

Figure 4 - Example of Google Trends based Sentiment Data

The keywords collected from the qualitative research (interviews) for sentiment index construction were then inputted into Google Trends tool to track the relative popularity of those words on Google Search engine using the default 0 to 100 scale that is available in the tool (see example above in Figure 4 for the keyword "recession"). To avoid any adjustments in relative popularity of the words with respect to each other, each keyword was inputted one at a time into the tool to generate sentiment index data. Summary statistics for the words' popularity were calculated using Microsoft Excel. The mean and standard deviation were then used to create standardized z-score metrics for the popularity values for each word over the given time range. This was done to provide comparability in data across both the time periods.

As stock market data was only available in a month-by-month format, the weekly format of the words' standardized popularity values was aggregated to a monthly format. For certain words, popularity values from Google Trends were listed as ' $<1$ ' in the raw data files. These values were uniformly replaced with ' 0.5 .'

To understand if the relationship between sentiment and stock market behavior was only limited to the immediate time period or also in subsequent periods, lagging of variables was done in Microsoft Excel by shifting the time series of one of the variables and not the other. This data was then correlated with the unlagged time series of the other variable to compute Pearson Correlation Coefficient was used for measuring correlation. Lag periods of 0 , 1, 2, 3, 4, 5 and 6 months were applied on each of the sentiment index metrics, and then those metrics were correlated against unlagged small-cap and mid-cap index values., if the impact of sentiment on stock behavior immediate or delayed. Similar lag periods were applied on the small-cap and mid-cap index performance data and correlated against the unlagged sentiment index metrics to understand if stock behavior impacts sentiments on an immediate or delayed basis. Together, the two sets of correlations help understand if sentiments correlate to stock performance with a greater delay or if the stock performance has a delayed impact on sentiments, so as to better understand the relationship between investor emotions and behaviors. The reason to use lags from 0 to 6 months is to capture both near-term and longer-term relationships on a practical basis. The limitations of this lagging are (1) the same words used for sentiment analysis cannot be used both 2008-09 and 2020-21, and hence, the approach does not give perfect comparison of the effect of sentiments in a time frame for both periods; (2) the assumption that changes in variables have an impact on a monthly basis after lagging, while they may in reality occur in other time frames.

\section{Results}

\section{Expert Interviews}


Interviews with 6 experts in the investment industry resulted in several key insights, which are summarized in this section, under various headings based on the questions in the interviews. (See Interview questions in Appendix)

\section{Differences between 2020 and 2008 for Investors:}

The majority of experts interviewed in the study were of the view that in India the reference point in 2020 was rather different from 2008 for stock investors due to a number of factors. Investor maturity (the ability to make informed investment decisions and control emotions during gains and losses) is a key difference, with much higher maturity about stock market investments among investors in 2020. Another prominent difference is where the markets stood prior to the crisis. In 2008, the markets were experiencing a major bull run between 2004 and 2008 before the financial crisis started.

In contrast, prior to the start of global pandemic, both the market and Indian economy was already in a slowgrowth mode, and small and mid cap stocks had already seen declines in the past two years, and very little gains available to investors. Work from home and digital platforms, along with money saved from lockdown were features of 2020 that also make the reference point different as investors had more access to the markets as well as higher liquidity than normal.

\section{Loss-aversion behavior in 2020 versus 2008}

All experts agreed that in their experience, loss-aversion was stronger during 2008 than in 2020. In the years prior to the pandemic, investors had already experienced losses, while the opposite was true in 2008. As a result, there was more maturity to deal with losses and focus shifted to opportunities for gains in 2020-21. Younger demographic investors with longer time horizons in 2020 played a role as well in reducing loss-aversion. Based on prospect theory, that results in the two periods' having different intensities of loss aversions from each other due to difference reference points.

\section{Macro factors and policy measures that influenced investor behavior}

The experts interviewed in the study thought that the macroeconomic environment during the crisis was also quite different in 2020. Government stimulus to the economy and relatively lower interest rates helped stabilize and reduce fears in 2020 among investors. In contrast, in 2008, India's central bank had less powers and mainly focused on maintaining liquidity in the banking system rather than giving direct support to the economy.

\section{Emotions impacting investor behavior}

Interviewees felt that fear and greed are key emotions that drive investor behaviors. Fear can prevent participation in the markets due to loss aversion, and greed can increase market participation due to perception of gains opportunity. In the interviews' view, easier access to market participation, which was the case in 2020, can lead to action-oriented sentiment responses to price movement in the market. Investment in risky assets like small and mid-cap stocks can increase in such situations, and can reduce in other situations. After making losses on small and mid cap stocks in the past two years, investors had already got used to the feeling of loss, and were also keen to make profits in 2020 when opportunity was available by buying inexpensive stocks of small and mid-cap stocks (the BSE Small-cap index PriceEarnings ratio had dropped nearly 20\% - from 33 in Oct 2019 to 27 in Mar 2020; lower Price-Earnings ratio indicates a lower normalized price for the stock). This resulted in increased market participation as the market recovered. In 2008 , experiencing loss after a period of steady gains kept investors out of the market due to fear of losses.

\section{Using Sentiment metrics:}

Among the respondents, the views on use of sentiment metrics were divided - while some did not think sentiments can predict stock index performance, others felt that it can be a good predictor in short-term but needs to be used along with other data on the performance of the economy and companies. 


\section{Small and Mid-cap stock - how do investors behave towards them:}

In general, according to the experts interviewed in the study, an investor rally in small and mid-cap stocks lags behind and generally follows a rally in large cap stocks. Since large caps recovered faster in 2020, small and mid-caps also recovered and grew quickly in that crisis, compared to slower recoveries of all segments in 2008. Availability of more liquidity and already low prices of small and mid cap stocks in 2020 made the investor behavior different compared to 2008 .

\section{Which stock index represents investor behavior}

BSE Mid-cap, BSE Small-cap Index, Nifty 400, Nifty 500 were thought to be reliable indicators of small and mid-cap stock performance according to the experts in the study sample.

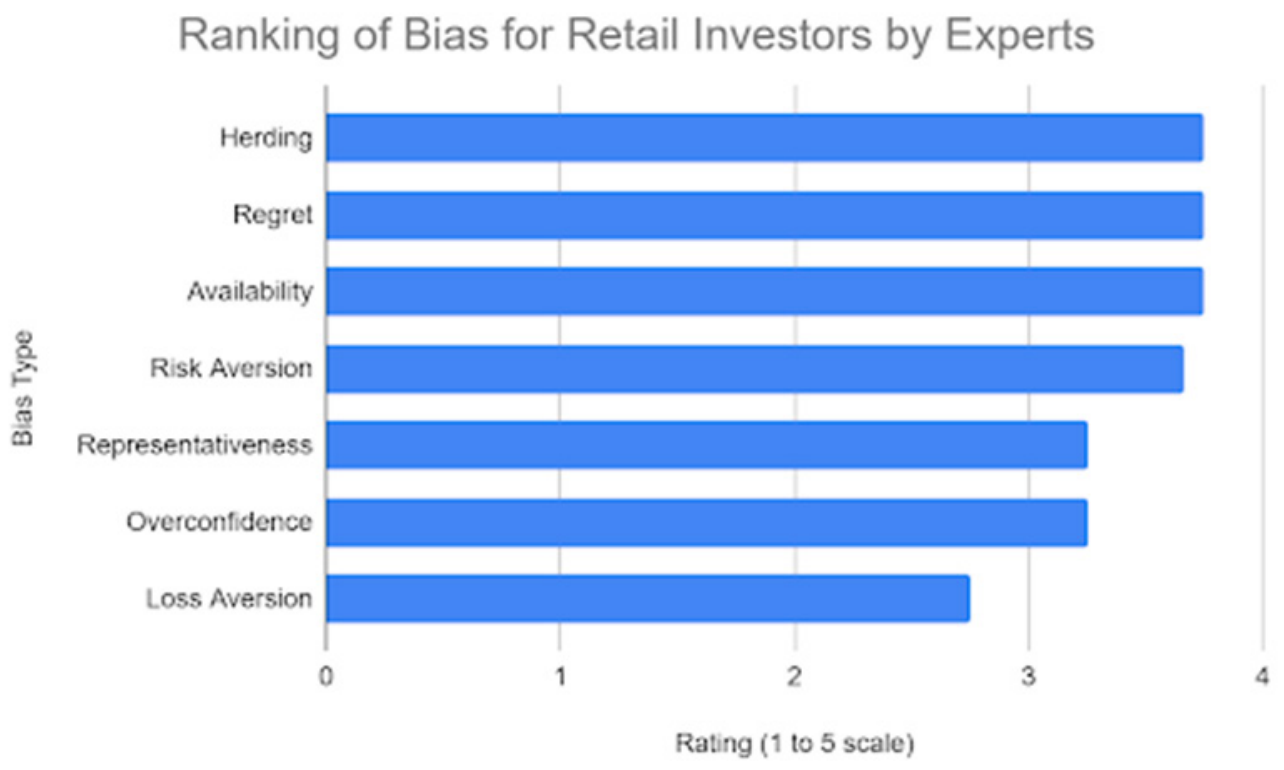

Figure 5: Ranking of Biases Most Frequently Seen with Retail Investors (Scale of 1-5, with 5 Most Influential and 1 Least Influential)

The ranking by experts (Figure 5) interviewed by study is consistent with the findings in literature research that herding is a very common form of bias in the Indian stock market, and other forms of bias like regret, availability, overconfidence also play an important role. While loss aversion was ranked lower than other biases in terms of relative incidence, it was still considered an important type of bias by the experts.

Based on the keywords that came up regularly in the interviews, the following words (Table 1) were finalized for the Sentiment Index metrics using Google Trends, keeping a mix of positive (hope) and negative (fear) words that retail investors may use to gather information on the markets. 


\begin{tabular}{|l|l|}
\hline 2008-09 Great Recession & 2020-21 Global Pandemic \\
\hline GROWTH (positive) & DEATH (negative) \\
\hline RECESSION (negative) & INFECTIONS (negative) \\
\hline INTEREST RATE (positive) & LOCKDOWN (negative) \\
\hline & INSURANCE (positive) \\
\hline & LIQUIDITY (positive) \\
\hline & STIMULUS (positive) \\
\hline
\end{tabular}

Table 1: List of Keywords Selected for Sentiment Index Computation in Google Trends

\section{Correlation Analysis of Sentiment Indices versus Stock Market Index}

\section{Stock Market Index Selection:}

S\&P Mid Cap 100 Index and S\&P Small Cap Index were used from BSE exchange, based on the expert feedback as well as availability of data for both time periods. NIFTY Mid Cap Index and NIFTY Small Cap Index were selected from the NSE exchange for additional analysis.

Based on correlation analysis of the stock indices, it was noted that the correlation between BSE S\&P Indices and NIFTY Indices was 0.99 for both small and mid-cap stocks. Additionally, the stock index for Small-cap and Midcap stocks are also correlated at 0.99 . To reduce duplication in information, the findings are discussed only for Smallcap stocks using the BSE S\&P Small-cap index, as mid-caps behaved practically identically to small-caps in both periods.

These correlations have been shown in Graphs 1-5 in the Appendix.

\section{Sentiment Index \& Time Period Selection:}

Time period of 24 months from the onset of the crisis was used for the analysis of correlations to ensure sufficient coverage of the movement of sentiments and stock prices. For the pandemic, the data for Aug 2020-Dec 2020 was removed during final analysis as the keywords showed very weak correlation (Pearson $r$ values in the range of 0 to $+/$ 0.2 ) with stock movement in that period.

For the 2008-09 crisis, all 3 keywords - "Growth", "Recession" and "Interest Rate" had sufficient correlation (greater than 0.3) to include in the analysis. However, for the 2020-21 period, the keywords "Death" and "Stimulus" were retained. The keywords "Infection", "Liquidity", "Lockdown" and "Insurance" were dropped from analysis due to very low correlations with stock index movement (less than 0.2).

Sentiment Index $(0,1,2,3,4,5$, and 6 months lag) correlated versus Unlagged Stock index. 
Lagged Sentiment versus Unlagged BSE Small-Cap Index - 2008 Great Recession

- "Growth" vs BSE - "Recession" vs BSE - "Interest Rate" vs BSE

1.00

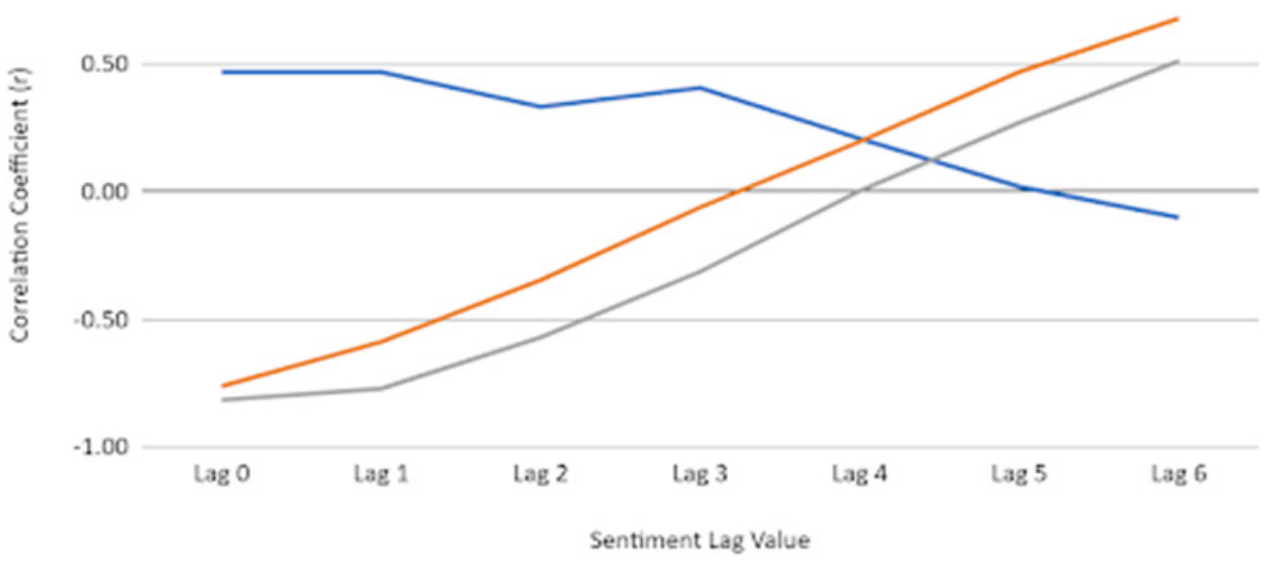

$\underline{\text { Figure } 6}$

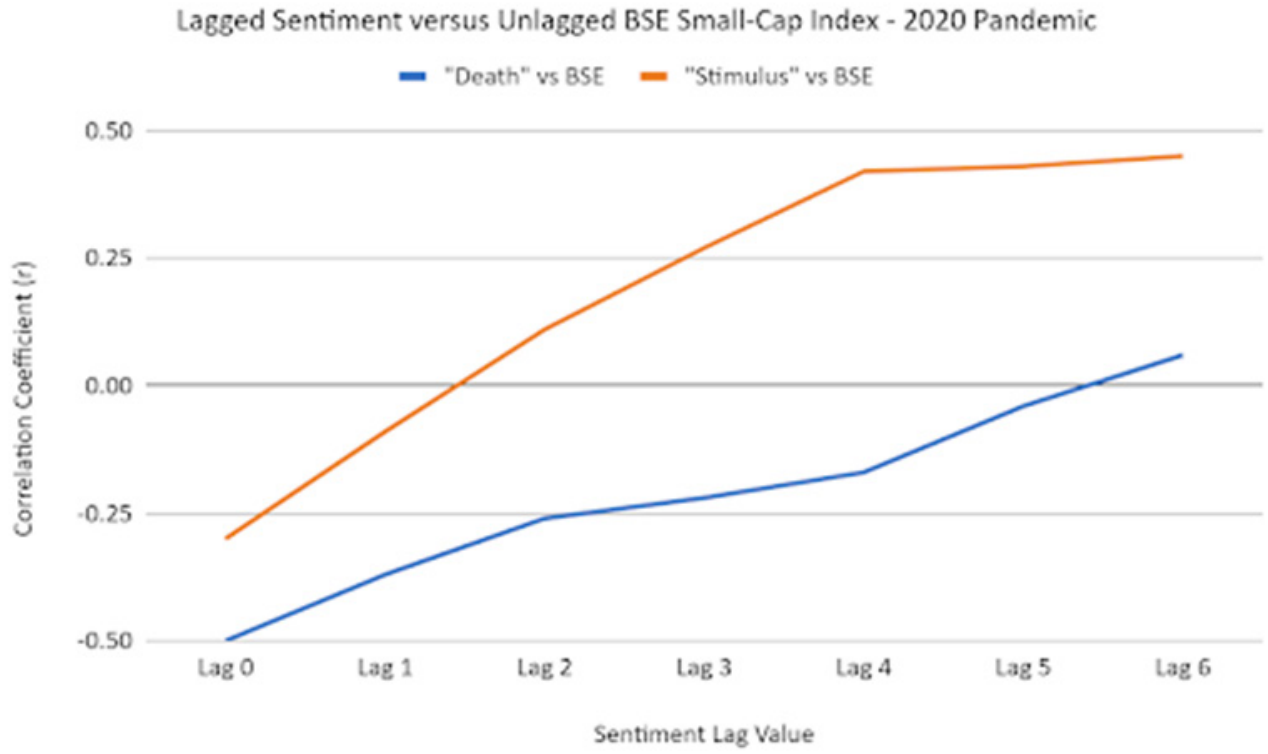

Figure 7

\section{Figure 6 \& 7 Summary}

The first salient observation is that the relationship between sentiments and stock index performance was stronger in 2008 (ranging from -0.8 to +0.7 ) compared to 2020 (ranging from -0.5 to +0.5 ).

In 2008, increased search for keyword "Growth" (positive sentiment) precedes positive movement in the stock indices more strongly in the first 3 months (short-term), and the lagged effect is much weaker, which indicates that positive sentiments have immediate impact. However, negative sentiments ( "Recession" and "Interest Rate") have a strong immediate negative association with stock index, and then drop off in the medium term, and then turns positive in the longer term (5-6 months). 
In 2020, strong negative sentiment (represented by search keyword "Death") also acts as strong immediate term precursors to decline in stock market performance (negative correlation), which indicates investors stay out of the market and are loss-averse in the short-term. However, the effect does not sustain in terms of lagged longer-term influence on market performance (correlation steadily weakens and is close to zero after 5-6 months). Similar to sentiment around "Interest Rate" in 2008, some sentiments (keyword "Stimulus") have a strong negative relationship with stock performance in the immediate term which shows loss-aversion, but a delayed positive relationship after a lag of 4-6 months.

Stock Index (with 0, 1, 2, 3, 4, 5, and 6 months lag) correlated versus unlagged Sentiment index.

Lagged BSE Small-Cap Index versus Unlagged Sentiment - 2008 Great Recession

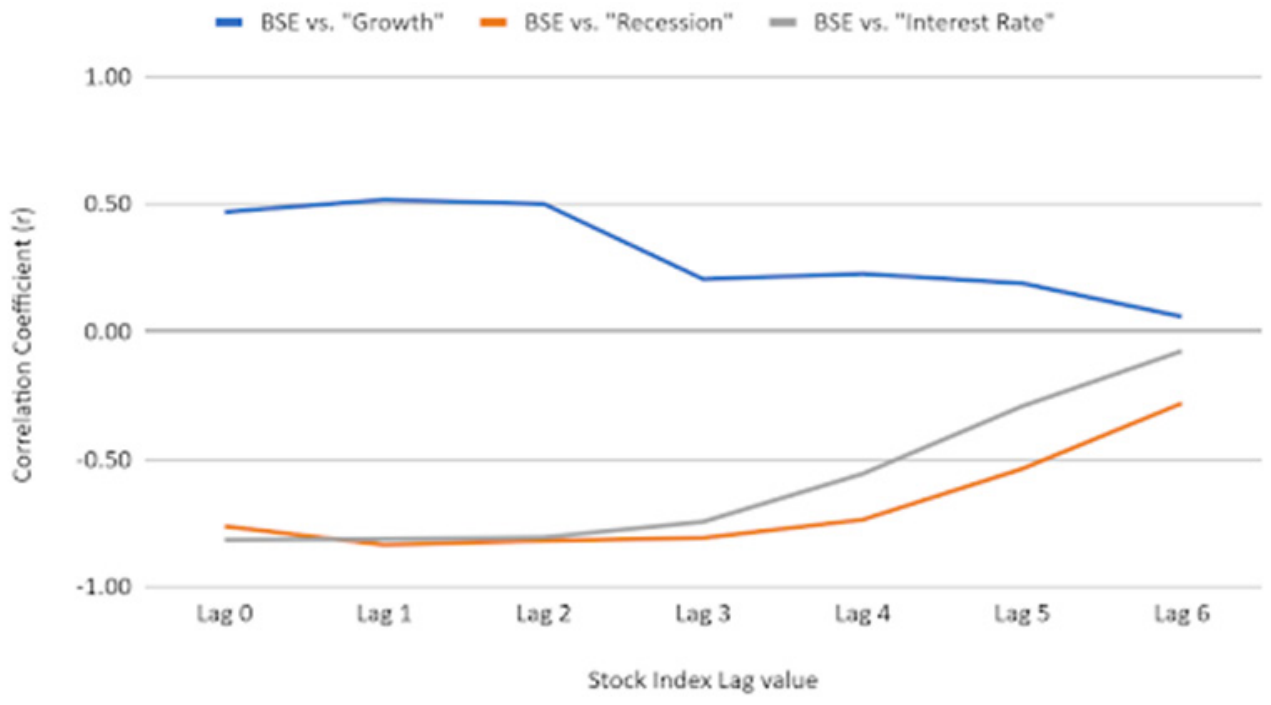

$\underline{\text { Figure } 8}$

Lagged BSE Small-Cap Index versus Unlagged Sentiment - 2020 Pandemic

- "Death" vs BSE - "Stimulus" vs BSE

0.2

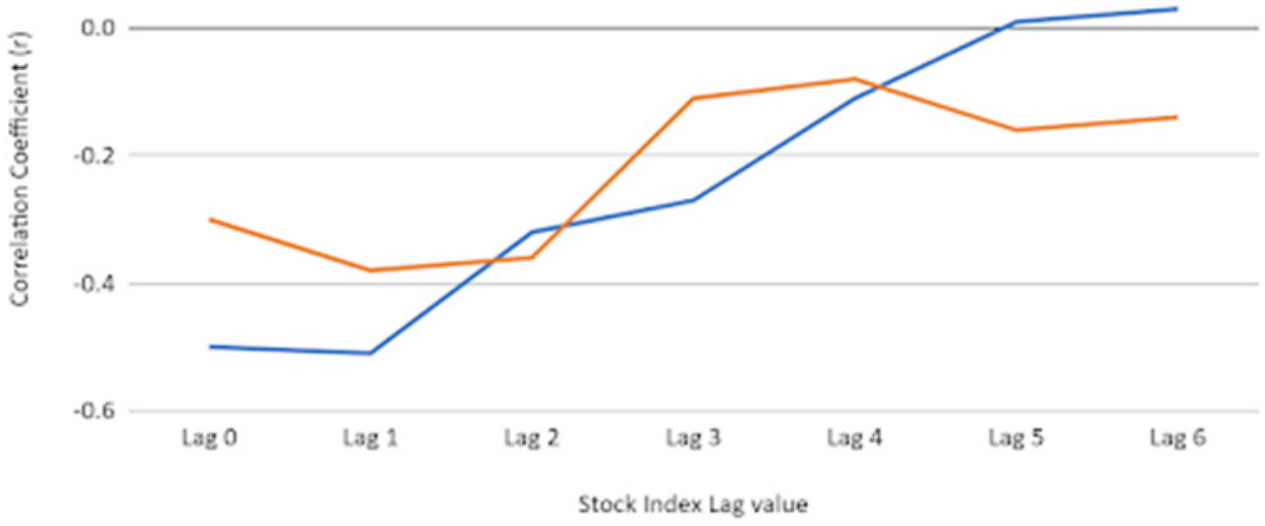

Figure 9

ISSN: 2167-1907

WWW.JSR.org 


\section{Figure 8 \& 9 Summary}

The key finding from Figure 8 and 9 is that stock index movement continues to have influence on investor sentiment over longer duration. This is in contrast to Figures 6 and 7 where lagging of sentiment produced a relationship that was more short-term in nature. As indicated in the Figure 8, the correlation coefficient for positive sentiment "Growth" remains higher than 0.2 (whether positive for "Growth" or negative for "Death" and "Stimulus") for at least up to 3 months when looking at lagged stock index versus unlagged sentiment, before declining to close to zero.

\section{Discussion}

Negative sentiments are more likely to have a negative influence on the stock indices in the immediate-term rather than longer-term, with investors becoming loss-averse and staying away from markets. Similarly, positive sentiments will have immediate term positive impact, with reduction in loss-aversion. In both cases, the longer-term or lagged relationship is weak and unclear.

However, the reverse relationship shows that movement of stock price has a more persistent influence on investor sentiments. A positive market movement correlated with reduced negative sentiments for several months (reducing loss-aversion for longer), and a negative market movement correlated with increased negative sentiment for several months (increasing loss-aversion for longer).

Finally, the results show that the sentiments used in the research fell into 3 categories - strong positive sentiment (i.e. keyword "Growth") which have positive relationship with stock market index in short-term and then diminishes ; strong negative sentiment (i.e. keyword "Death") which has a similar pattern to the one aforementioned, but in the negative direction; and, some sentiments (like keywords "Stimulus" and "Interest rate") that can have negative or positive association with stock market, depending on time horizon.

Both the expert interviews and correlation analysis indicate that the loss aversion (fear of loss stronger than hope of gains) around investments, particularly the more volatile small and mid-cap stocks, was higher in 2008 compared to 2020. As stated in the interviews, the context in 2020 was rather different from 2008 for various reasons (stock market trends in India prior to the event, new demographics, new investing platforms, government intervention, liquidity etc.), which perhaps made investors more comfortable with the idea of losses during the 2020-21 pandemic. This supports one of the key tenets of prospect theory that framing or reference point plays an important role in determining degree of loss aversion among individuals.

While positive sentiments have positive influence in short-term and vice versa for negative sentiments, further research is required to understand the nature of some sentiments that seem to increase loss-aversion in short-term and reduce it in longer term.

Finally, it is also observed that fluctuations in the stock market index have a more persistent influence on sentiments over time (when index performance is lagged and correlated against sentiment changes) than fluctuations in sentiments (lagged sentiment changes). In the expert interviews it was suggested that herding behavior was one of Indian investors' most prominent biases. Correlation analysis suggests that loss-aversion (or its reversal) can be influenced by herding behavior as investors follow what the market is doing. In this study, herding behavior seems to be stronger in 2008-09 compared to 2020-21, and maybe because of the greater maturity of investors in 2020-21. However, further research may be required to understand this more definitively.

\section{Limitations}


First, retail investors are only a minority of total investors in the Indian stock market, with the majority being institutional investors. Stock market movement is impacted by both retail and institutional investors. In this study it is assumed that movement in stock market indices is a good representation of retail investor behavior and not distorted by institutional investors.

Second, In the interval between 2009 and 2020, several changes in policy, demographics, investing technology and global trade have taken place that have contributed to the changes in investor behavior observed in 2020 . The paper tries to note a few of those (younger investors, inexpensive and convenient digital investing platforms, better investment information on the internet etc.) but not all may have been included. Further research should look into the role of those as well.

Finally, loss-aversion bias is one of the many biases influencing investor behavior in the Indian market, as discussed in earlier sections of this paper. This study did not control for other types of biases that may have also influenced the relationship between investor sentiment and stock performance in different ways during the two periods. There was some evidence of herding bias playing a role, particularly during the 2008 recession. Therefore, the results in this study provide directional evidence on the direct role of loss-aversion in these two periods, which needs to be further evaluated in future studies involving other types of biases.

\section{Conclusion}

This paper intended to determine the differences in investor behavior during 2008 compared to 2020 through the lens of prospect theory. Results indicate that positive sentiment and negative sentiment have immediate-term positive and negative relationship respectively with investor behavior, and this relationship was noticeably stronger during the 2008 recession compared to the pandemic. This shows how loss aversion was stronger in the long-run during 2008 than during 2020, but the influence of sentiments on investor behavior was not longer-term in nature. Also, the reference point plays a role in the smaller magnitude of loss-aversion in 2020 compared to 2008, as there was greater government intervention, internet search engine use, younger investors, prior experience with losses, and free-trade platforms. These findings are consistent with prospect theory in terms of the role of reference point in determining degree of loss-aversion. However, further research may be needed to understand why the influence does not persist longer-term.

These results have multiple other implications. Firstly, this paper adds to the limited current literature on Indian retail investor behavior during the 2020-21 and 2008-09 crises, and is a starting point to comparing these two periods in India. Secondly, the results show how governments and financial firms can provide policy and trading platform assistance to create a more conducive environment for investors to trade in risky financial assets, and to reduce likelihood of loss-aversion bias. Third, further study is required to understand why movement in the stock market has a longer-term consequence on investor sentiment that follows, as it may be related to other biases like Herding etc.. Lastly, the difference in the cause of the two crises shows how investors perceive gains and losses differently in different environments or reference points, which suggests that prospect theory and loss-aversion behaviors can be seen at work in practical conditions, whether it is a health pandemic or a banking related economic crisis.

\section{Acknowledgments}

I would like to thank several people who helped me write and publish this paper. Firstly, my mentor Zoey Chopra for his guidance in helping me think through each stage of the research process in order to make original contributions to the literature on the topic. Secondly, Nischitha Suresh and Prakriti Sharma for helping me organize my schedule to write this paper. Lastly, Stephen Turban and Dhruva Bhat, co-founders of Lumiere Education, for inspiring my academic research journey. 


\section{Bibliography}

Bhaduri, Saumitra N., and Siddharth D. Mahapatra. "Applying an Alternative Test of HERDING Behavior: A Case Study of the Indian Stock Market." Journal of Asian Economics 25 (2013): 43-52. Print.

Oliveira-Brochado, Ana. "Google Search Based Sentiment Indexes." IIMB Management Review 32.3 (2019): $325-$ 35. Print.

Chandra, Abhijeet, and Ravinder Kumar. "Factors Influencing Indian Individual Investor Behavior: Survey Evidence." SSRN Electronic Journal (2012): 141-67. Print.

Dhall, Rosy, and Bhanwar Singh. "The COVID-19 Pandemic and Herding Behavior: Evidence FROM India's Stock Market." Millennial Asia 11.3 (2020): 366-90. Print.

Dutta, Abhijit, Madhabendra Sinha, and Padmabati Gahan. "Perspective of the Behavior of Retail Investors: An Analysis with Indian Stock Market Data." Advances in Intelligent Systems and Computing (2019): 605-16. Print.

Hall, M. (2021, May 18). What is market efficiency? Investopedia. Retrieved December 8, 2021, from https://www.investopedia.com/insights/what-is-market-efficiency/.

Hirvonen, Tommy. "BEHAVIORAL FINANCE IN FINANCIAL CRISES: THE CASE OF COVID-19." Aalto University School of Business (2020): 1-77. Print.

Islam, I., and S. Verick. "The Great Recession Of 2008-09: Causes, Consequences and Policy Responses." From the Great Recession to Labour Market Recovery (2011): 19-52. Print.

Kahneman, Daniel, and Amos Tversky. "Prospect Theory: An Analysis of Decision under Risk." Econometrica 47.2 (1979): 263-92. Print.

KONSTANTINIDIS, A., KATARACHIA, A., BOROVAS, G., \& VOUTSA, M. E. (2012). From Efficient Market Hypothesis To Behavioural Finance: Can Behavioural Finance Be The New Dominant Model For Investing? Scientific Bulletin - Economic Sciences, University of Pitesti, 11(2), 16-26.

Mushinada, Venkata Narasimha. "How Do Investors Behave in the Context of a Market CRASH? Evidence from India." International Journal of Emerging Markets 15.6 (2020): 1201-217. Print.

Ortmann, Regina, Matthias Pelster, and Sascha Tobias Wengerek. "COVID-19 and Investor Behavior." SSRN Electronic Journal 37 (2020). Print.

Poshakwale, Sunil, and Anandadeep Mandal. "Investor Behavior AND Herding: Evidence from the National Stock Exchange in India." Journal of Emerging Market Finance 13.2 (2014): 197-216. Print.

Shawn, L. K. J., \& Stridsberg, D. (2015). Feeling the Market's Pulse with Google Trends. International Federation of Technical Analysts' Journal.

Vasileiou, Evangelos. "Behavioral Finance and Market Efficiency in the Time of the Covid-19 Pandemic: Does Fear Drive the Market?" International Review of Applied Economics 35.2 (2020): 224-41. Print. 
WHO Director-General's opening remarks at the media briefing on COVID19 - 11 March 2020 [Google Scholar]

Wikipedia contributors. "COVID-19 lockdown in India." Wikipedia, The Free Encyclopedia. Wikipedia, The Free Encyclopedia, 5 Dec. 2021. Web. 7 Dec. 2021. 